\title{
A probabilistic fuzzy goal programming model for managing the supply of emergency relief materials
}

\author{
Rabin K. Jana ${ }^{1}$ (D) Dinesh K. Sharma² Peeyush Mehta ${ }^{3}$
}

Accepted: 30 August 2021 / Published online: 15 September 2021

(C) The Author(s), under exclusive licence to Springer Science+Business Media, LLC, part of Springer Nature 2021

\begin{abstract}
The post-disaster humanitarian logistic operations deal with the supply of emergency relief materials to mitigate damages in the affected areas. Immediately after the disaster, it is challenging to estimate the demand for emergency relief materials. As a result, the demand for such materials at the point of demand and the corresponding transportation costs for the entire supply chain network becomes uncertain. This paper proposes a new probabilistic fuzzy goal programming model for making decisions to manage the post-disaster supply of emergency relief materials. A suggested procedure converts the proposed model to its deterministic equivalent when the demands for the relief materials follow uniform distributions. We implement the differential evolution, a metaheuristic technique, for analyzing demand satisfaction for relief materials under various scenarios. A case example based on the Nepal Earthquake in 2015 demonstrates the usefulness of the proposed approach. The solution of the model will help the Disaster Management Agency coordinate with the humanitarian organizations and foreign countries to provide the required emergency relief materials so that an adequate level of supply can be assured to the affected areas with the least possible transportation cost.
\end{abstract}

Keywords Disaster relief operations · Humanitarian aid · Probabilistic fuzzy goal programming $\cdot$ Differential evolution

Rabin K. Jana

rkjana@iimraipur.ac.in

Dinesh K. Sharma

dksharma@umes.edu

Peeyush Mehta

pmehta@iimcal.ac.in

1 Operations and Quantitative Methods Area, Indian Institute of Management Raipur, Atal Nagar, CG 493661, India

2 Department of Business, Management and Accounting, University of Maryland Eastern Shore, Princess Anne, MD 21853, USA

3 Operations Management Area, Indian Institute of Management Calcutta, Kolkata, WB 700104, India 


\section{Introduction}

Natural and anthropogenic disasters have a devastating effect on essential services. In such situations, allocation, and supply of emergency relief materials (RM) to those in need are the most critical activities of disaster relief operations. These activities aim to save lives and alleviate the human suffering of survivors (Yu et al., 2021; Zhu et al., 2019). As per the United Nations Office for the Coordination of Humanitarian Affairs, about 134 million people were provided humanitarian assistance in 2018 (UN OCHA, 2018). The joint humanitarian response plans of the UN show that approximately $72 \%$ of the affected people received some sort of international humanitarian support, and only $28 \%$ received domestic humanitarian aid. Therefore, managing the supply of emergency RM in the post-disaster phase is crucial (Dubey \& Gunasekaran, 2016; Jana et al., 2019).

Scholars study various aspects of managing the post-disaster supply of emergency RM. These include logistics planning for shipping multiple items (Özdamar et al., 2004), removing bottlenecks of the supply network (Day et al., 2012), arriving at the best transportation decisions (Park et al., 2018; Wang et al., 2016a); exploring the involvement of private sector players in supplying RM (Tomasini and Van Wassenhove, 2009), and integrating the local and responding foreign organizations (Day, 2014), etc. The decision-making environment in such situations witnesses conflicting goals evolving from the structure of the relief chain, nature of operations, and incomplete or lack of information about the demand, supply, and cost of emergency RM (Bozorgi-Amiri et al., 2013).

The common cause of uncertainty in supply is a delay in supplying the RM from the suppliers. Most of the time, it is difficult to know about the availability of resources and predict the contribution of suppliers (Abazari et al., 2020). Uncertainty in demand is caused by inaccurate assessments that are obvious in the immediate post-disaster situation (Liu et al., 2018). Uncertainty in the cost is mainly caused by the ambiguity related to the selection of routes, mode of transportation, and suppliers. Consequently, mathematical models focusing on managing the supply of emergency RM must address the two major issues-uncertainty in available information and achieving conflicting goals in post-disaster situations.

This research proposes a mathematical model that can simultaneously capture the probabilistic and fuzzy uncertainties and quantify the trade-offs between the total cost of supplying the RM and demand satisfaction for post-disaster humanitarian logistic operations. Such a model is important as it will better capture the uncertainties of the decision environment. Consequently, the model will help make superior decisions related to humanitarian aid delivery in complex disaster situations. The existing humanitarian logistics (HL) literature has a scarcity of such models. The present research will void this critical gap in the HL literature.

The objective of this research is to model the disaster response planning for supplying emergency RM to the affected areas, defined as a point of demands (PD), in the response phase by capturing the innate uncertainty existing in various components like cost, supply, and demand. Emergency RM are to be supplied to the PD where actual requirements are not known with certainty. So, the demands for the RM are defined as random variables. Consequently, the overall cost of transporting the RM are also not known with certainty. Therefore, the level of satisfaction of the goals in such a situation is ambiguous. As a result, the goals of the model become probabilistic and fuzzy 
simultaneously. Thus, a novel probabilistic fuzzy goal programming model is proposed to tackle this challenging emergency RM supply problem. The problem is finally solved using differential evolution, an artificial intelligence-based search technique.

This research contributes to the existing humanitarian supply chain literature in the following ways:

- Achieving a unique relief logistics model for supplying the emergency RM to different layers of PD that contemplates various sources uncertainties in the relief chain. This is crucial as uncertainties in the relief chain make decision-making very challenging.

- Developing a novel probabilistic fuzzy goal programming model to deal with the postdisaster supply of RM and deriving its equivalent model under the assumption of uniform demands and overall total cost of supplying the RM.

- Applying the proposed model to a real-world post-disaster situation to manage the supply of emergency RM.

The paper is organized as follows. Section 2 presents the literature review. Section 3 describes the problem under study and the mathematical model. Section 4presents the methodology. Section 5 presents a case example based on the 2015 Nepal earthquake. Section 6 presents the results and discussions. Section 7 presents the theoretical and managerial implications, and Sect. 8 concludes the paper.

\section{Literature review}

The aftermath of any disaster necessitates an immediate supply of emergency RM to minimize human sufferings (Dubey \& Gunasekaran, 2016; Wang et al., 2016b; Behl \& Dutta, 2020a; Behl \& Dutta, 2020b; Shafiq \& Soratana, 2020; Cao et al., 2021). Because of various trade-offs and uncertainty in the decision-making environment (Maiyar \& Thakkar, 2020), it is always challenging to achieve this goal during execution (Dubey et al., 2019a; Özdamar et al., 2004). Authors study the humanitarian aid delivery problem under uncertainty in demand and cost (Faiz \& Vogiatzis, 2020; Liu \& Nagurney, 2013; Sun et al., 2018; Tofighi et al., 2016; Zokaee et al., 2016), demand and carbon price (Rezaee et al., 2017), estimated arrival times, travel time and cost, transportation plan risk (Zheng \& Ling, 2013), the response time (Bastian et al., 2016), loading-unloading time (Abazari et al., 2020), inventory amounts (Cao et al., 2021), etc. Majorly, the concepts of two-stage stochastic programming (Grass \& Fischer, 2016). In some cases, two-stage stochastic programming is combined with other techniques like variational inequality theory (Liu $\&$ Nagurney, 2013). A section of literature utilized the robust optimization technique for addressing similar problems (Faiz \& Vogiatzis, 2020; Liu et al., 2018; Zokaee et al., 2016). The most important shortcoming of the models used in these studies is the inability to capture the trade-offs arising in the disaster relief chain. In other words, these models can accommodate a single criterion.

Goal programming (GP) and its variants are known for measuring the trade-offs among goals that are conflicting in nature (Papathanasiou \& Ploskas, 2018; Sharma et al., 2009). GP models have been successfully applied to access the trade-offs in humanitarian supply chain management (Vitoriano et al., 2009; Hong et al., 2015; Charles et al., 2016; Ransikarbum \& Mason, 2016; Chong, 2019). These models fail to incorporate the trade-offs under probabilistic uncertainty. For example, in the disaster relief distribution considered 
in this work, the supply of emergency RM to the PD, located in multiple layers and accessible through a specific mode of transportation, under demand and cost uncertainties. The existing relief supply chain models in the HL literature cannot solve such a problem. To overcome this disadvantage, we develop a model utilizing the concepts of probabilistic fuzzy goal programming (PFGP) (Jana et al., 2016; Mohamed, 1992) for managing the supply of emergency RM under uncertainty. Table 1 summarizes some of the important optimization models on the relief supply chain, highlighting their key characteristics to distinguish the novelty of the proposed model from the existing literature. This is the only model that can accommodate the objective function related to the relief supply chain with probabilistic goals with fuzzy satisfaction levels. Because of this typical structure of the goals, the proposed model becomes unique and challenging for finding the solution.

The proposed PFGP model is solved by a population-based genetic type artificial intelligence (AI) algorithm, known as Differential evolution (DE). The DE algorithm was proposed by Storn and Price (1997). The algorithm has been applied to solve problems from different domains, as documented in the literature (Das \& Suganthan, 2010). There are few applications of DE in the area of SCM (Routroy \& Kodali, 2005; Yu et al., 2020) and stochastic SCM (Lieckens \& Vandaele, 2016), two-stage humanitarian logistic under uncertainty (Tofighi et al., 2016), and supply allocation for disaster relief operations (Chen et al., 2020). So, there are ample scopes of application of DE for solving the problem related to the supply of emergency RM and set the motivation for selecting the technique.

\section{Problem formulation}

Disasters cause severe damage to the underlying infrastructure facilities like the supply of electricity, water, transportation, and telecommunication. This leads to uncertainty in receiving information about the number of affected peoples and the demands of life-saving humanitarian aid. Thus, ensuring the supply of life-saving resources for the affected people is critical to alleviating the impact of the disaster (Dubey et al., 2019b). Countries worldwide, humanitarian agencies, NGOs, etc., extend their support in various ways, including the supply of life-saving relief materials to disaster-affected countries. Most of such relief materials are transported through cargo planes, and some are through ships. These points are denoted as Main Point-of-Entries (MPE). The country's Disaster Management Agency (DMA) will coordinate with the entire supply process of the humanitarian aid received from foreign countries, humanitarian organizations, and internal sources. Aid received from the internal sources may be collected and supplied to some distribution centers that act as MPE. In our modeling, we treat these two types of sources of humanitarian aid as MPE.

\subsection{Assumptions}

The following assumptions are developed based on United Nations World Food Programme (UN-WFP) (2015), and the UNWFP, Situation Report 21.05.2015:

a. There will be a limited number of MPE from where the supply will take place to the affected areas. 


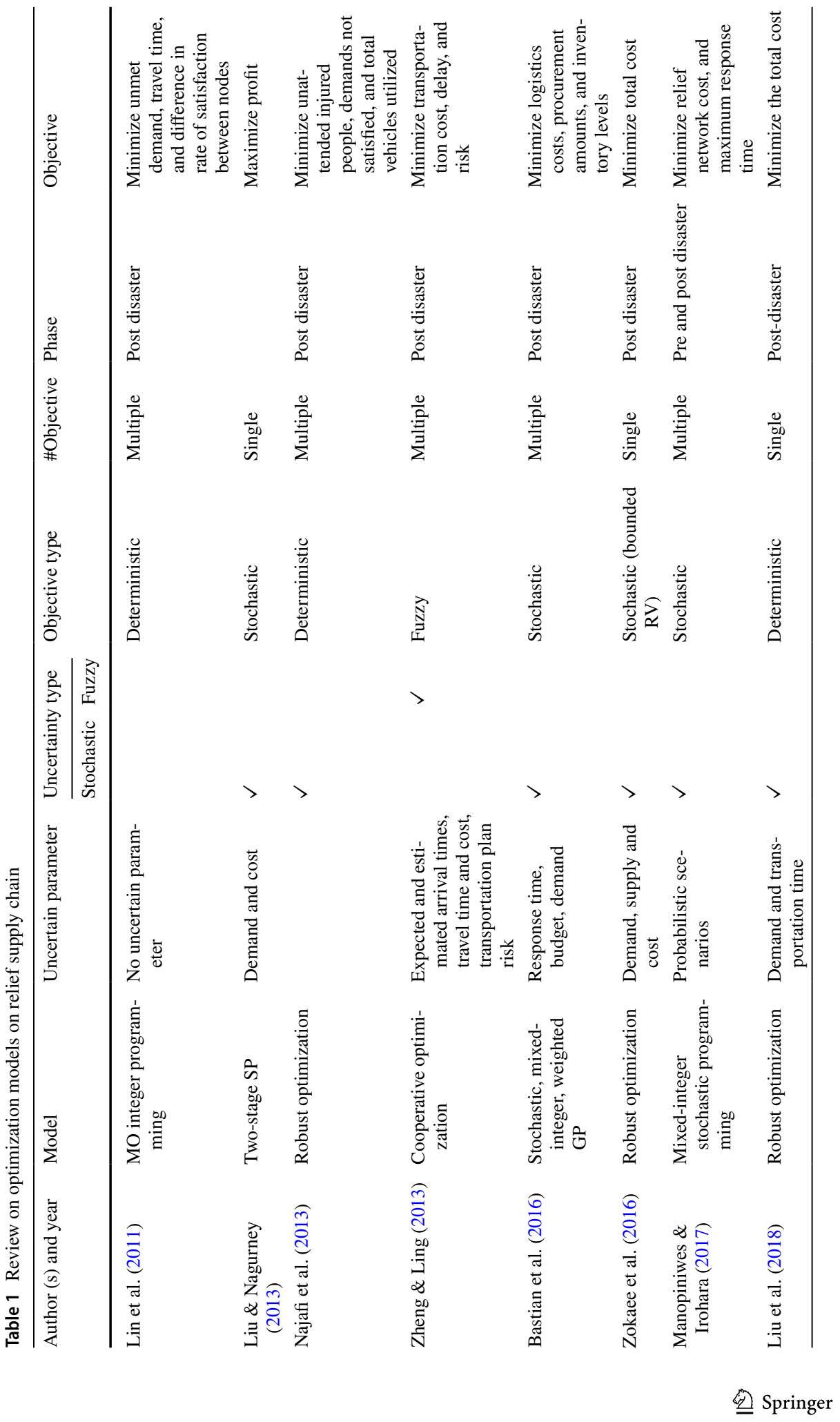




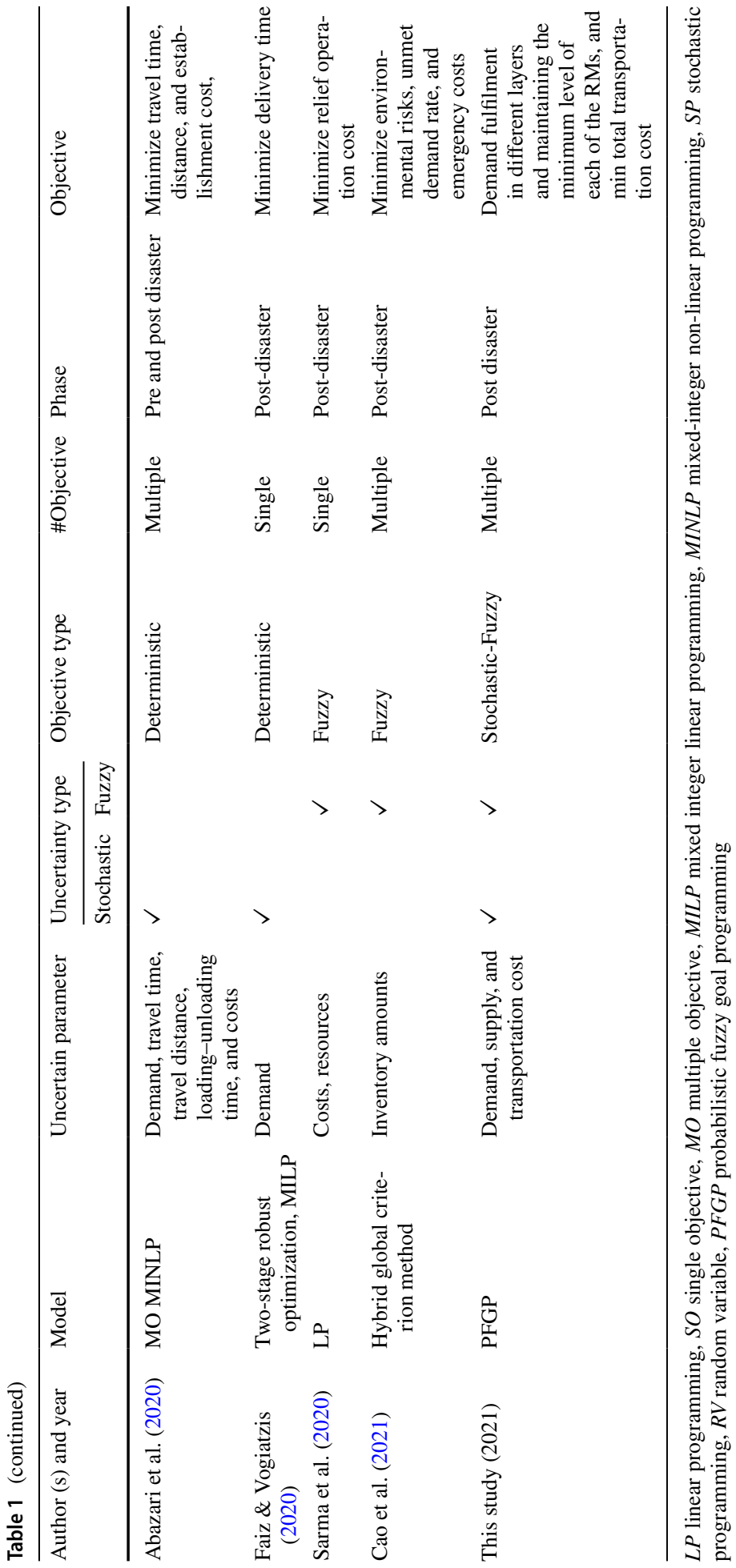


b. We consider the supply of essential aid into three layers - Layer 1, Layer 2, and Layer 3. Layer 1 locations are accessible through major roads from the MPE. Relief materials will be directly sent to these locations by road transport.

c. There are two types of locations in Layer 1-staging areas (SA) and PD. SA are the temporary storage places from where the relief materials will be transported to PD located in Layer 2 and Layer 3. PD located in Layer 1 will receive relief materials directly from the MPEs through the roadways.

d. PD in Layer 2 are not accessible from the MPE. They are accessible from the SAs using mini transport vans.

e. PD in Layer 3 are remote and not accessible through roadways. Helicopters, porters, or a combination must be utilized to reach the affected people and deliver the relief materials.

Table 2 Notations and descriptions

\begin{tabular}{|c|c|}
\hline Notation & Description \\
\hline$x_{m e s}$ & $\begin{array}{l}\text { Amount of relief material of type } m(m=1,2, \ldots, M) \text { transported from M-PE } e(e=1,2, \ldots, E) \text { to } \\
\text { SA } s(s=1,2, \ldots, S) \text { through main road/highway, an integer decision variable }\end{array}$ \\
\hline$x_{m e p_{1}}^{L 1}$ & $\begin{array}{l}\text { Amount of relief material of type } m(m=1,2, \ldots, M) \text { transported from M-PE } e(e=1,2, \ldots, E) \text { to } \\
\text { POD } p_{1}\left(p_{1}=1,2, \ldots, P_{1}\right) \text { in Layer-1 through main road/highway, an integer decision variable }\end{array}$ \\
\hline$x_{m s p_{2}}^{L 2}$ & $\begin{array}{l}\text { Amount of relief material of type } m(m=1,2, \ldots, M) \text { transported from SA } s(s=1,2, \ldots, S) \text { to } \\
\text { POD } p_{2}\left(p_{2}=1,2, \ldots, P_{2}\right) \text { in Layer-2 through narrow roads, an integer decision variable }\end{array}$ \\
\hline$x_{m s p_{3}}^{L 3}$ & $\begin{array}{l}\text { Amount of relief material of type } m(m=1,2, \ldots, M) \text { transported from SA } s(s=1,2, \ldots, S) \text { to } \\
\text { POD } p_{3}\left(p_{3}=1,2, \ldots, P_{3}\right) \text { in Layer-3 through air transportation, an integer decision variable }\end{array}$ \\
\hline$R_{m e}$ & Amount of relief material of type $m(m=1,2, \ldots, M)$ available at the M-PE $e(e=1,2, \ldots, E)$ \\
\hline$c_{\text {mes }}$ & $\begin{array}{l}\text { Unit transportation cost of relief material of type } m(m=1,2, \ldots, M) \text { transported from M-PE } \\
e(e=1,2, \ldots, E) \text { to SA } s(s=1,2, \ldots, S) \text { through main road/highway }\end{array}$ \\
\hline$c_{m e p_{1}}^{L 1}$ & $\begin{array}{l}\text { Unit transportation cost of relief material of type } m(m=1,2, \ldots, M) \text { transported from M-PE } \\
e(e=1,2, \ldots, E) \text { to POD } p_{1}\left(p_{1}=1,2, \ldots, P_{1}\right) \text { in Layer-1 through main road/highway }\end{array}$ \\
\hline$c_{m s p_{2}}^{L 2}$ & $\begin{array}{l}\text { Unit transportation cost of relief material of type } m(m=1,2, \ldots, M) \text { transported from SA } \\
s(s=1,2, \ldots, S) \text { to POD } p_{2}\left(p_{2}=1,2, \ldots, P_{2}\right) \text { in Layer- } 2 \text { through narrow roads }\end{array}$ \\
\hline$c_{m s p_{3}}^{L 3}$ & $\begin{array}{l}\text { Unit transportation cost of relief material of type } m(m=1,2, \ldots, M) \text { transported from SA } \\
s(s=1,2, \ldots, S) \text { to POD } p_{3}\left(p_{3}=1,2, \ldots, P_{3}\right) \text { in Layer- } 3 \text { through air transportation }\end{array}$ \\
\hline$\tilde{D}_{m}^{L 1}$ & Demand of relief material of type $m(m=1,2, \ldots, M)$ in Layer-1, a random variable \\
\hline$\tilde{D}_{m}^{L 2}$ & Demand of relief material of type $m(m=1,2, \ldots, M)$ in Layer- 2 , a random variable \\
\hline$\tilde{D}_{m}^{L 3}$ & Demand of relief material of type $m(m=1,2, \ldots, M)$ in Layer-3, a random variable \\
\hline$\tilde{T}_{C}$ & Targeted total transportation cost for all the relief materials, a random variable \\
\hline$\tilde{R}_{D}$ & Anticipated demand for all the relief materials of relief items, a random variable \\
\hline$L_{m s}^{S A}$ & $\begin{array}{l}\text { Minimum amount of relief material of type } m(m=1,2, \ldots, M) \text { to be stored at the SA } \\
\quad s(s=1,2, \ldots, S)\end{array}$ \\
\hline$S_{m s}^{S A}$ & Storage capacity of relief material of type $m(m=1,2, \ldots, M)$ at SA $s(s=1,2, \ldots, S)$ \\
\hline$\alpha$ & Satisfaction level of the cost goal \\
\hline$\beta_{m}^{1}$ & Satisfaction level of the demand goals in Layer 1 for relief material of type $m(m=1,2, \ldots, M)$ \\
\hline$\beta_{m}^{2}$ & Satisfaction level of the demand goals in Layer 2 for relief material of type $m(m=1,2, \ldots, M)$ \\
\hline$\beta_{m}^{3}$ & Satisfaction level of the demand goals in Layer 3 for relief material of type $m(m=1,2, \ldots, M)$ \\
\hline
\end{tabular}




\section{Notations}

The probabilistic fuzzy goal programming model for supplying humanitarian aid in the early phase of the disaster is developed with the help of the following notations (Table 2):

\subsection{Model objectives}

There are two broad categories of objectives in the proposed model. The first category of objectives is related to the satisfaction of the demands of relief materials at the three layers. As the demands are uncertain, the corresponding cost of supplying the relief materials is also uncertain. Consequently, both types of objectives are expressed probabilistically. Also, there is no guarantee of satisfaction of the objectives in a strict sense in the uncertain demand situation. Therefore, satisfaction levels of the objectives are expressed fuzzily.

\subsubsection{Demand for relief material}

The demand goal for the relief material $m(m=1,2, \ldots, M)$ at Layer 1 can be expressed as follows:

$$
\operatorname{Pr}\left\{\sum_{e=1}^{E} \sum_{p_{1}=1}^{P_{1}} x_{m e p_{1}}^{L 1} \geq \tilde{D}_{m}^{L 1}\right\} \gtrsim \beta_{m}^{1}, \quad m=1,2, \ldots, M
$$

where $\tilde{D}_{m}^{L 1}$ is a random variable.

The demand goal for the relief material $m(m=1,2, \ldots, M)$ at Layer 2 can be expressed as follows:

$$
\operatorname{Pr}\left\{\sum_{s=1}^{S} \sum_{p_{2}=1}^{P_{2}} x_{m s p_{2}}^{L 2} \geq \tilde{D}_{m}^{L 2}\right\} \gtrsim \beta_{m}^{2}, \quad m=1,2, \ldots, M
$$

where $\tilde{D}_{m}^{L 2}$ is a random variable.

The demand goal for the relief material $m(m=1,2, \ldots, M)$ at Layer 3 can be expressed as follows:

$$
\operatorname{Pr}\left\{\sum_{s=1}^{S} \sum_{p_{3}=1}^{P_{3}} x_{m s p_{3}}^{L 3} \geq \tilde{D}_{m}^{L 3}\right\} \gtrsim \beta_{m}^{3}, \quad m=1,2, \ldots, M
$$

where $\tilde{D}_{m}^{L 3}$ is a random variable.

The left-hand side expression of Eq. (1) under the probability represents the total amount of relief material of type $m(m=1,2, \ldots, M)$ transported from M-PE $e(e=1,2, \ldots, E)$ to POD $p_{1}\left(p_{1}=1,2, \ldots, P_{1}\right)$ in Layer-1 through the main road/highway, and the right-hand side represents the demand of relief material of type $m(m=1,2, \ldots, M)$ in Layer-1. Similarly, we can explain Eqs. (2) and (3).

\subsubsection{Transportation cost}

The transportation cost goal has four components. The first component represents the cost of transporting relief materials from the MPEs to SAs. The second component represents the cost of transporting the relief materials from the MPEs to PD located in Layer 1. The 
third component represents the cost of transporting the relief materials from the SA to PD located in Layer 2. The fourth component represents the cost of transporting the relief materials from the SA to PD located in Layer 3. The cost goal can be expressed as follows:

$$
\operatorname{Pr}\left\{\sum_{m=1}^{M} \sum_{e=1}^{E} \sum_{s=1}^{S} c_{m e s} x_{m e s}+\sum_{m=1}^{M} \sum_{e=1}^{E} \sum_{p_{1}=1}^{P_{1}} c_{m e p_{1}}^{L 1} x_{m e p_{1}}^{L 1}+\sum_{m=1}^{M} \sum_{s=1}^{S} \sum_{p_{2}=1}^{P_{2}} c_{m s p_{2}}^{L 2} x_{m s p_{2}}^{L 2}+\sum_{m=1}^{M} \sum_{s=1}^{S} \sum_{p_{3}=1}^{P_{3}} c_{m s p_{2}}^{L 3} x_{m s p_{3}}^{L 3} \leq \tilde{T}_{C}\right\} \gtrsim \alpha
$$

where $\tilde{T}_{C}$ is a random variable.

Equation (1) represents the demand goal for the RM at Layer 1. This goal aims to satisfy the demand for relief material of a specific type, ensuring a minimum level of satisfaction. The level of satisfaction is also not guaranteed and hence expressed fuzzily. The other two demand goals presented in Eqs. (2) and (3) for the RM at Layer 2 and 3, respectively, can also be explained similarly. Equation (4) represents the transportation goal. This goal ensures the probability of total transportation cost to be less than the targeted total transportation cost for all the relief materials with a minimum level of satisfaction. The level of satisfaction is also expressed fuzzily.

\subsection{Model constraints}

The proposed model considers three major types of constraints. The first set of constraints ensures that the total supply from the MPEs should not exceed the available relief materials. The second set of constraints ensures the storage of some amount of relief materials at the SA to combat the situations of sudden demand. The last set of constraints is related to the capacity of SA.

\subsubsection{Supply from MPE}

Relief material of type $m(m=1,2, \ldots, M)$ received at the SA is less than the available amounts in the MPEs.

$$
\sum_{e=1}^{E} \sum_{s=1}^{S} x_{m e s}+\sum_{s=1}^{S} \sum_{p_{1}=1}^{P_{1}} x_{m s p_{1}}^{L 1} \leq \sum_{e=1}^{E} R_{m e}, \quad m=1,2, \ldots, M
$$

\subsubsection{Storage of relief materials at the SA}

A minimum amount of relief material of type $m(m=1,2, \ldots, M)$ must be stored at each SA to meet the sudden demand and avoid the crisis.

$$
\sum_{e=1}^{E} x_{m e s}-\sum_{p_{2}=1}^{P_{2}} x_{m s p_{2}}^{L 2}-\sum_{p_{3}=1}^{P_{3}} x_{m s p_{3}}^{L 3} \geq L_{m s}^{S A}, \quad m=1,2, \ldots, M ; s=1,2, \ldots, S
$$

\subsubsection{Storage capacity of SA}

Each SA has a maximum capacity for storing various relief items. The relief items received from the MPE must not exceed the storage capacity of SA. 


$$
\sum_{e=1}^{E} x_{m e s}+L_{m s}^{S A} \leq S_{m s}^{S A}, \quad m=1,2, \ldots, M ; s=1,2, \ldots, S
$$

So, the mathematical model contains probabilistic-fuzzy goals corresponding to the demands of relief material to be satisfied at the three Layers and transportation cost, subject to constraints for supply from MPE, storage of relief materials at the SA, and storage capacity of SA.

\section{Methodology}

The proposed methodology has two components. The first component presents a unique approach to deal with the probabilistic fuzzy goals corresponding to the demands of different emergency relief materials at the PD belonging to the affected areas and the overall transportation cost. The second component summarizes differential evolution, an artificial intelligence approach, to solve the problem.

\subsection{The proposed model}

The probabilistic fuzzy goal programming model can be represented as follows (Mohamed, 1992):

$$
\begin{gathered}
\operatorname{Pr}\left\{G_{i}(x) \geq T_{i}\right\} \gtrsim \beta_{i}, \quad i=1,2, \ldots, I \\
\text { subject to } \quad A x \leq B
\end{gathered}
$$

$$
\mathrm{x} \geq 0
$$

where $\boldsymbol{x}$ is the vector of decision variables. In the above formulation, $\tilde{\mathrm{c}}_{\mathrm{kj}}(\mathrm{k}=1,2, \cdots, \mathrm{K} ; \mathrm{j}=1,2, \cdots, \mathrm{n}) \mathrm{T}_{\mathrm{i}}$ are random variables with known probability distributions. Each probabilistic goal is satisfied with fuzzily.

The $i$-th goal $\operatorname{Pr}\left\{G_{i}(\boldsymbol{x}) \geq T_{i}\right\} \gtrsim \beta_{i}$ represents the desired level of satisfaction to be at least $\beta_{i}$, however, a relaxation of $\beta_{i}^{L}$, say, may also be permitted to accommodate the uncertainty of the decision-making environment. This is very relevant to our case in which the demands of emergency relief materials are not known with certainty. Let us assume that the target is to satisfy at least $98 \%$ of the demands of relief materials at a particular Layer. Under this setting, it is possible to achieve a $100 \%$ satisfaction level if all constraints are satisfied. However, we may allow a relaxation of $3 \%$, say, and ready to accept a solution in which the demand goal is satisfied with the satisfaction of $95 \%$. This solution will surely be a little inferior compared to the initial target satisfaction level, but at the same time will be highly acceptable as an implementable solution considering the uncertainty of the decision environment. If $\mu_{i}(\boldsymbol{x})$ be the membership function corresponding to the $i$-th goal $\operatorname{Pr}\left\{G_{i}(x) \geq T_{i}\right\} \gtrsim \beta_{i}$, then it can be formulated as: 


$$
\mu_{i}(x)= \begin{cases}1 & \text { if } \operatorname{Pr}\left\{G_{i}(x) \geq T_{i}\right\} \geq \beta_{i} \\ \frac{\operatorname{Pr}\left\{G_{i}(x) \geq T_{i}\right\}-\left(\beta_{i}-\beta_{i}^{L}\right)}{\beta_{i}^{L}} & \text { if } \beta_{i}-\beta_{i}^{L} \leq \operatorname{Pr}\left\{G_{i}(x) \geq T_{i}\right\}<\beta_{i} \\ 0 & \text { if } \operatorname{Pr}\left\{G_{i}(x) \geq T_{i}\right\}<\beta_{i}-\beta_{i}^{L}\end{cases}
$$

Proposition 1 Problem (8)-(10) can equivalently be formulated as:

$$
\max : \quad \sum_{i=1}^{I} \lambda_{i}
$$

Subject to $\operatorname{Pr}\left\{G_{i}(\boldsymbol{x}) \geq T_{i}\right\} \geq\left(\beta_{i}-\beta_{i}^{L}\right)+\beta_{i}^{L} \lambda_{i}, \quad i=1,2, \ldots, I$

$$
A x \leq \mathrm{B}
$$

$$
x \geq 0
$$

Proof For the complete satisfaction of the k i-th goal $\operatorname{Pr}\left\{G_{i}(x) \geq T_{i}\right\} \gtrsim \beta_{i}$, its corresponding membership value $\lambda_{i}\left(0 \leq \lambda_{\mathrm{i}} \leq 1\right)$ should be one (Narasimhan, 1980). The maximum value of $\lambda_{i}$ is one. Therefore, the objective will be to maximize $\lambda_{i}$ and reach the target threshold subject to $\mu_{i}(\boldsymbol{x}) \geq \lambda_{i}$, and system constraints. Following Zimmermann (1978), the relationship can be written for all $i=1,2, \ldots, I$ as follows:

$$
\begin{aligned}
& \max : \sum_{i=1}^{I} \lambda_{i} \\
& \mu_{i}(\boldsymbol{x}) \geq \lambda_{i}, \quad i=1,2, \ldots, I
\end{aligned}
$$

Using (11), the relationship (17) can be expressed as follows:

$$
\operatorname{Pr}\left\{G_{i}(\boldsymbol{x}) \geq T_{i}\right\} \geq\left(\beta_{i}-\beta_{i}^{L}\right)+\beta_{i}^{L} \lambda_{i}, \quad i=1,2, \ldots, I
$$

This completes the proof.

In (18), $T_{i}, \forall i=1,2, \ldots, I$ are random variables with a known probability distribution. Theoretically, each $T_{i}$ can follow any suitable probability distribution. In a real-world situation, the distribution of $T_{i}$ may be estimated based on available data or assumed based on known facts. In the considered problem of supplying emergency relief materials under uncertainty, demand may be defined to vary between some estimated upper and lower bounds. So, it may be realistic to assume that the probability distribution of demands of relief materials follows a uniform distribution.

Proposition 2 If $T_{i} \sim U\left(T_{a_{i}}, T_{b_{i}}\right)$, then (18) reduces to:

$$
G_{i}(\boldsymbol{x}) \geq T_{a_{i}}+\left\{\left(\beta_{i}-\beta_{i}^{L}\right)+\beta_{i}^{L} \lambda_{i}\right\}\left(T_{b_{i}}-T_{a_{i}}\right), \quad i=1,2, \ldots, I
$$

Proof As $T_{i} \sim U\left(T_{a_{i}}, T_{b_{i}}\right)$, the density function is. 


$$
f_{i}\left(T_{i}\right)= \begin{cases}\frac{1}{T_{b_{i}}-T_{a_{i}}} & \text { if } T_{a_{i}} \leq T_{i} \leq T_{b_{i}} \\ 0 & \text { otherwise }\end{cases}
$$

The cumulative distribution function is given by (Lusk \& Wright, 1982),

$$
f_{i}\left(T_{i}\right)= \begin{cases}\frac{T_{i}-T_{a_{i}}}{T_{b_{i}}-T_{a_{i}}} & \text { if } T_{a_{i}} \leq T_{i} \leq T_{b_{i}} \\ 1 & \text { if } T_{i} \geq T_{b_{i}}\end{cases}
$$

Therefore, (19) is equivalent to

$$
G_{i}(\boldsymbol{x}) \geq K_{\gamma_{i}}
$$

where

$$
\gamma_{i}=\left\{\left(\beta_{i}-\beta_{i}^{L}\right)+\beta_{i}^{L} \lambda_{i}\right\}
$$

where $K_{\gamma_{i}}$ is the solution of

$$
\gamma_{i}=\frac{K_{\gamma_{i}}-T_{a_{i}}}{T_{b_{i}}-T_{a_{i}}}
$$

Hence,

$$
K_{\gamma_{i}}=T_{a_{i}}+\gamma_{i}\left(T_{b_{i}}-T_{a_{i}}\right)
$$

Using (23) and (25) in (22), we get (19). This completes the proof.

So, the problem (12)-(15) reduces to

$$
\max : \quad \sum_{i=1}^{I} \lambda_{i}
$$

subject to $G_{i}(\boldsymbol{x}) \geq T_{a_{i}}+\left\{\left(\beta_{i}-\beta_{i}^{L}\right)+\beta_{i}^{L} \lambda_{i}\right\}\left(T_{b_{i}}-T_{a_{i}}\right), \quad i=1,2, \ldots, I$

$$
\begin{gathered}
A x \leq \mathrm{B} \\
\mathrm{x} \geq 0
\end{gathered}
$$

\subsection{Differential evolution (DE)}

The DE is a population-based, stochastic search technique extensively used to solve various types of optimization problems (Storn \& Price, 1997). It works similarly to other metaheuristics. However, it shows uniqueness in terms of the use of direction and distance information of the present population to steer the search process. The basic operations of DE are mutation, crossover, and selection. An initial population of candidate solutions needs to be generated first. This is done by generating uniform random numbers within a given upper and lower bounds. Potential new solutions are introduced into the population by performing mutation and crossover operations. Parent solutions are replaced by new solutions (children) if they possess better fitness values. The DE algorithms have been 
applied to various problem domains and work well for large problem instances as well (Das et al., 2016). We present the necessary steps of the DE in the following pseudocode:

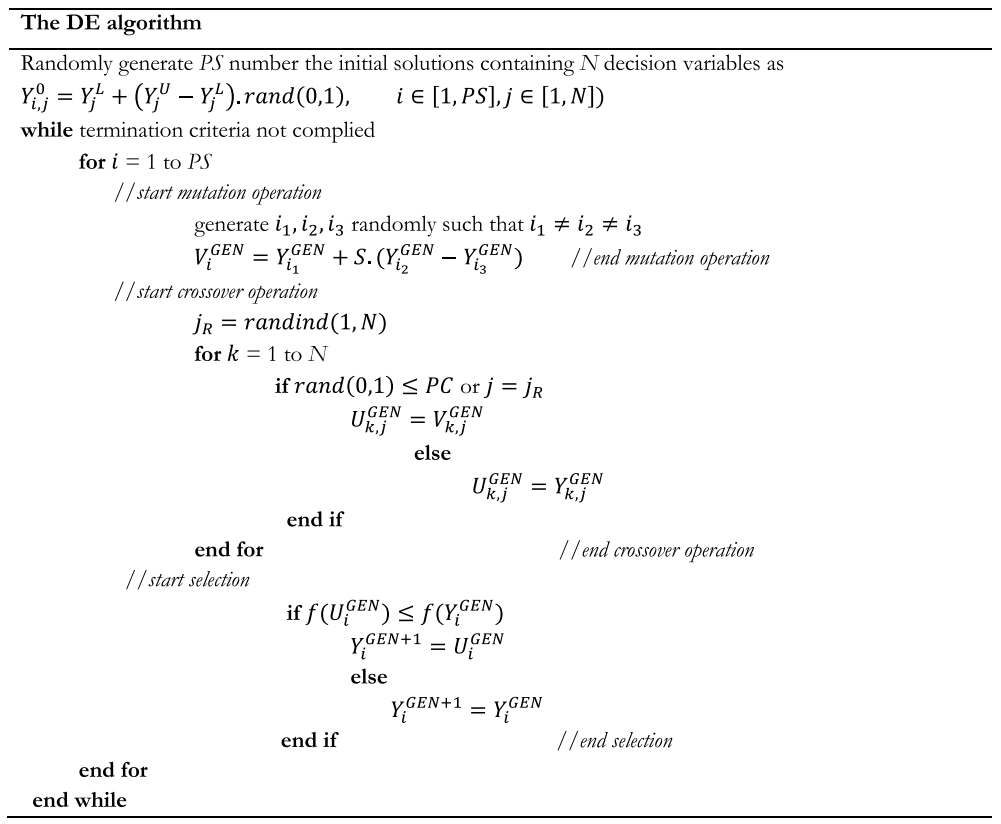

In the pseudocode, $P S$ denotes the population size, $S$ denotes the scaling factor for mutation, $P C$ denotes the probability of crossover, $N$ denotes the number of decision variables, $G E N$ denotes the number of generations, $\operatorname{rand}($.) denotes the uniform random number generator; $Y_{i}^{G E N}$ denotes the target vector, $Y_{j}^{U}$ denotes the upper limit of the $j$-th variable, $Y_{j}^{L}$ denotes the lower limit of the $j$-th variable, $V_{i}^{G E N}$ denotes the $N$ component donor vector obtained from the mutation operation, $U_{i}^{G E N}$ denotes the $N$ component trial vector obtained from the crossover operation, and $f$ denotes the fitness function.

\section{A case example}

We develop this case example based on the 2015 Nepal Earthquake. The rationale for using Nepal Earthquake for this study is highlighted here. We want to verify the effectiveness of the proposed PFGP model to a real-world and complex disaster relief supply problem. As a result, we initially study different disaster relief operations that happened in the past decades. We look to model the disaster relief supply situation mathematically. The evidence suggests that the 2015 Nepal Earthquake was a major natural calamity of the previous decade. The existence of affected areas that are (i) accessible through major roads, (ii) accessible from the staging areas using mini transport vans due to narrow road conditions, and (iii) not accessible through roadways have provided us to consider a three-layer relief distribution problem. Now, uncertainties exist in all the layers. Consequently, the nature of 
the problem is more complex compared to the disaster relief distribution problem with the requirement of resource materials in a single or two layers.

On April 25, 2015, a strong earthquake had a magnitude of 7.8 struck Nepal. Out of 28.9 million people, approximately 8 million people were affected (NPC, 2015). A total of 22,302 people was injured, 198 people were missing, and 8,970 people were deceased. Damages were reported from more than 50 districts of Nepal. The 14 worst-hit districts were Gorkha, Lamjung, Dhading, Nuwakot, Rashuwa, Kavre, Sindhupalchok, Dolakha, Ramechhap, Okhaldhunga, Sindhuli, Kathmandu, Bhaktapur, and Lalitpur. The earthquake was devastating mainly due to the poor infrastructure of Nepal, especially in the mountainous rural areas where the houses were made of mud, timbers, and stacked stones. The total number of houses fully damaged was 604,930 , and partially damaged was 288,856 . The number of people who needed humanitarian assistance was 2.8 million (NPC, 2015). The earthquake was marked as the deadliest earthquake to strike in the region in the past 81 years.

Immediately after the disaster, the Government of Nepal and various humanitarian organizations started the rescue work. Due to the scarcity of drinking water, lack of toilets, and the temporary nature of living conditions, there were concerns about epidemics. UNICEF appealed for donations. People were in desperate need of first-aid materials, food, drinking water, sanitation kits, and temporary shelters. More than sixty-five countries, including various Government and humanitarian aid agencies, started to supply essential relief materials to Kathmandu (UN-WFP, 2015).

In this case example, we consider the supply of six emergency relief materialsfirst-aid materials (FA), dry food (DF), water (WA), sanitation kits (SK), tents (TT), and blankets (BT) to the affected areas. Most of these items are received as humanitarian aid. All such items are received at the Tribhuvan International Airport (TIA), Kathmandu, the country's main airport. The TIA is defined as the Main Point-of-Entry (MPE) (UN-WFP), (2015). The majority of the emergency relief items are received at the MPE. Relief items received at the MPE must be supplied to the people of affected areas. The affected areas needing the relief items are defined as Point-of-Demands (PD). We consider three layers of PD. The first layer (Layer 1) PD can get the supply directly from the MPE due to the uninterrupted road connectivity. The second layer (Layer 2) PD are the areas that are not connected by narrow roads. The supply of relief materials is possible using small transport vehicles. The third layer of (Layer 3) PD are the areas that are disconnected from the rest of the country due to avalanches. Layer 3 PD are accessible through air and porters, or a combination of both. To ensure the supply of

Table 3 Demand estimates of relief materials at Layers 1,2 and 3

\begin{tabular}{lllll}
\hline & RM & Layer 1 & Layer 2 & Layer 3 \\
\hline Demand & FA & $U(12,000,13,000)$ & $U(36,000,40,000)$ & $U(16,000,17,000)$ \\
& DF & $U(20,000,22,000)$ & $U(60,000,64,000)$ & $U(24,500,25,500)$ \\
& WA & $U(25,000,27,000)$ & $U(70,000,75,000)$ & $U(33,500,35,500)$ \\
& SK & $U(10,000,11,000)$ & $U(30,000,32,000)$ & $U(13,000,14,000)$ \\
& TT & $U(4000,4500)$ & $U(15,000,16,000)$ & $U(7500,8000)$ \\
& BT & $U(18,000,20,000)$ & $U(60,000,65,000)$ & $U(29,500,31,500)$ \\
\hline
\end{tabular}

$U(a, b)$ denotes the uniform random variable defined between $a$ and $b$ 
emergency relief materials to PD in Layer 2 and Layer 3, Staging Areas (SA) are designated at places that are accessible from the MPE through the major roadways. So, relief materials can be supplied to the SA by heavy transport vehicles. Helicopter facilities are not available at all SA. Therefore, relief materials may be supplied to PD in Layer 3 from designated SA only.

Data used in the study were collected from various sources, including the United Nations World Food Programme (UN-WFP), (2015), a leading agency that coordinates the logistics activities in the humanitarian response, NPC (2015), CDPS, (2016) Government of Nepal Official Website, Government of Nepal Transport Department, and Baharmand et al. (2020). We followed a similar supply chain network structure as implemented by UN-WFP (2015). Temporary SA were built to store the relief materials and supply them to the PD according to the estimated demands. The eight SA are Dhulikhel (SA1), Bharatpur (SA2), Deurali (SA3), Chautara (SA4), Dhading Besi (SA5), Bidur (SA6), Dhunche (SA7), and Charikot (SA8). SA1 and SA2 are designated as major distribution hubs in which helipad facilities are available (UN-WFP, Situation Report May 21, 2015). So, relief materials are supplied from these two SA to all the PD in Layer 3. The number of PD selected in Layer 1, Layer 2, and Layer 3 are 3, 12, and 8, respectively. Due to space constraints, data on transportation cost from MPE to SA, PD in Layer 1, from SA to PD in Layer 2 and Layer 3, minimum storage of relief materials in SA, and storage capacity of SA are not mentioned in the paper. They may be available on request from the authors.

\section{Results and discussion}

This section offers the results of the proposed model obtained using the DE approach. According to the considered number of RM, MPE, SA, PD, the model (26)-(29) is formulated. This model consists of 301 variables and 157 constraints. Out of the 301 variables, 282 are decision variables, and the remaining 19 are membership functions corresponding to the goals. All $\beta_{i}$ are taken as 0.9 and all $\beta_{i}^{L}$ are taken as 0.05 . So, the minimum value of the satisfaction probability of each goal is $90 \%$. The model is implemented in R ( R Core Team, 2013), and 'DEoptimR' function (Schwendinger, 2019) is used in the code. All the computations are done in a PC having processor Intel(R) Core(TM) i5-7200 CPU @ $2.50 \mathrm{GHz} 2.71 \mathrm{GHz} 8 \mathrm{~GB}$ RAM, 64 bits operating system. The execution time for all the case instances is less than one minute.

The estimated demands of six RM at Layers 1, 2, and 3 are presented in Table 3.

As demands of RM are random variables, we investigate different scenarios about their satisfaction. Demands satisfaction at Layers 1, 2, and 3 will depend on the availability of $\mathrm{RM}$ at the MPE. Our analysis will help in making crucial decisions in this matter. The following scenarios are considered:

Scenario $170 \%$ of overall demand satisfaction for RM at Layer 1, 2, and 3.

Scenario $280 \%$ of overall demand satisfaction for RM at Layer 1, 2, and 3.

Scenario $390 \%$ of overall demand satisfaction for RM at Layer 1, 2, and 3.

Scenario 4 100\% of overall demand satisfaction for RM at Layer 1, 2, and 3. 


\subsection{Scenario $1.70 \%$ of overall demand satisfaction for RM at Layer 1, 2, and 3}

The solution obtained for Scenario 1 is as follows. The notations used are self-explanatory and defined previously.

$x_{111}=13,425, x_{112}=300, x_{113}=7700, x_{114}=300, x_{115}=4700, x_{116}=7700, x_{117}=$ $7700, x_{118}=300, x_{211}=18,815, x_{212}=24,660, x_{213}=9000, x_{214}=1000, x_{215}=1000$, $x_{216}=1000, x_{217}=1000, x_{218}=14,000, x_{311}=1000, x_{312}=39,000, x_{313}=6105, x_{314}=$ $1000, x_{315}=1000, x_{316}=9000, x_{317}=14,000, x_{318}=14,000, x_{411}=10,165, x_{412}=400$, $x_{413}=4600, x_{414}=2930, x_{415}=4600, x_{416}=4600, x_{417}=7600, x_{418}=400, x_{511}=5782$, $x_{512}=200, x_{513}=2269, x_{514}=200, x_{515}=200, x_{516}=3800, x_{517}=3800, x_{518}=2096$, $x_{611}=22,480, x_{612}=27,160, x_{613}=9500, x_{614}=500, x_{615}=500, x_{616}=9500, x_{617}=500$, $x_{618}=500 . x_{111}^{L 1}=9065, x_{211}^{L 1}=15,330, x_{311}^{L 1}=18,830, x_{411}^{L 1}=7665, x_{511}^{L 1}=3132, x_{611}^{L 1}=$ $13,930, x_{211}^{L 2}=1260, x_{223}^{L 2}=23,660, x_{323}^{L 2}=13,220, x_{623}^{L 2}=26,660, x_{135}^{L 2}=7400, x_{235}^{L 2}=$ $8000, x_{336}^{L 2}=5105, x_{435}^{L 2}=4200, x_{535}^{L 2}=2069, x_{635}^{L 2}=9000, x_{446}^{L 2}=2530, x_{157}^{L 2}=4400, x_{457}^{L 2}=$ $4200, x_{169}^{L 2}=7400, x_{369}^{L 2}=8000, x_{469}^{L 2}=4200, x_{569}^{L 2}=3600, x_{669}^{L 2}=9000, x_{1811}^{L 2}=7400$, $x_{3811}^{L 2}=13,000, x_{4811}^{L 2} \stackrel{369}{=} 7200, x_{5811}^{L 2} \stackrel{4}{=} 3600, x_{2812}^{L 2} \stackrel{569}{=} 13,000, x_{3812}^{L 2}=13,000, x_{5812}^{L 2}=1896$, $x_{111}^{L 3}=11,865, x_{211}^{L 3}=17,815, x_{411}^{L 3}=9765, x_{511}^{L 3}=5582, x_{611}^{L 3}=21,980, x_{326}^{L 3}=24,780$.

We summarize the solution obtained in Scenario 1 in the case when the objective is to satisfy $70 \%$ of the overall demand of relief materials at Layer 1, 2, and 3 as follows:

From the above solution, we find that the supply of $9065,27,860$, and 11,865 boxes of first-aid materials (FA) must be ensured to satisfy the demands at Layer 1, 2, and 3, respectively. Similarly, the supply of 15,330, 44,660, and 17,815 packets of dry food (DF) must be ensured to satisfy the demand at Layer 1,2, and 3, respectively. The supply of $18,830,52,325$, and 24,780 quantity of water (WA) pouches must be ensured to satisfy the demands at Layer 1, 2, and 3, respectively. The supply of 7665, 22,330, and 9765 packets of sanitation kits (SK) must be ensured to satisfy the demands at Layer 1, 2, and 3, respectively. The supply of $3132,11,165$, and 5582 pieces of tents (TT) must be ensured to satisfy the demands at Layer 1, 2, and 3, respectively. Finally, the supply of 13,930, 44,660, and 21,980 pieces of blankets (BT) must be ensured to satisfy the demands at Layer 1, 2, and 3, respectively. The above results will help the disaster management team to plan and maintain the above-mentioned minimum quantities of relief materials to be made available at the MPE to satisfy $70 \%$ of the overall demand at three different layers.

\subsection{Scenario $2.80 \%$ of overall demand satisfaction for RM at Layer 1, 2, and 3}

The solution obtained for Scenario 2 is as follows:

$x_{111}=1117, x_{112}=19,700, x_{113}=7700, x_{114}=300, x_{115}=4700, x_{116}=7700, x_{117}=$ $6283, x_{118}=300, x_{211}=21,360, x_{212}=15,040, x_{213}=9000, x_{214}=1000, x_{215}=9000$, $x_{216}=9000, x_{217}=1000, x_{218}=14,000, x_{311}=17,120, x_{312}=39,000, x_{313}=1000, x_{314}=$ $1000, x_{315}=1000, x_{316}=9000, x_{317}=14,000, x_{318}=14,000, x_{411}=14,600, x_{412}=3080$, $x_{413}=4600, x_{414}=400, x_{415}=4600, x_{416}=4600, x_{417}=7600, x_{418}=400, x_{511}=6580$, $x_{512}=200, x_{513}=200, x_{514}=200, x_{515}=3800, x_{516}=3800, x_{517}=2160, x_{518}=3800$, $x_{611}=29,500, x_{612}=29,500, x_{613}=500, x_{614}=500, x_{615}=660, x_{616}=9500, x_{617}=500$, $x_{618}=9500 . x_{111}^{L 1}=10,360, x_{211}^{L 1}=17,520, x_{311}^{L 1}=21,520, x_{411}^{L 1}=8760, x_{511}^{L 1}=3580, x_{611}^{L 1}=$ $15,920, x_{411}^{L 2}=3040, x_{611}^{L 2}=3880, x_{123}^{L 2}=6657, x_{223}^{L 2}=14,040, x_{323}^{L 2}=25,800, x_{423}^{L 2}=2680$, $x_{623}^{L 2}=29,000, x_{135}^{L 2}=7400, x_{235}^{L 2}=8000, x_{435}^{L 2}=4200, x_{157}^{L 2}=4400, x_{257}^{L 2}=8000, x_{457}^{L 2}=$ $4200, x_{557}^{L 2}=3600, x_{658}^{L 2}=160, x_{169}^{L 2}=7400, x_{269}^{L 2}=8000, x_{369}^{L 2}=8000, x_{469}^{L 2}=4200, x_{569}^{L 2}=$ $3600, x_{669}^{L 2}=9000, x_{1811}^{L 2}=5983, x_{3811}^{L 2}=13,000, x_{4811}^{L 2} \stackrel{2}{=} 7200, x_{5811}^{L 2}=1960, x_{2812}^{L 2}=$ 
$13,000, x_{3812}^{L 2}=13,000, x_{5812}^{L 2}=3600, x_{6812}^{L 2}=9000, x_{111}^{L 3}=817, x_{211}^{L 3}=20,360, x_{311}^{L 3}=$ $16,120, x_{411}^{L 3}=11,160, x_{511}^{L 3}=6380, x_{611}^{L 3}=25,120, x_{128}^{L 3}=12,743, x_{265}^{L 3}=12,200$.

We summarize the solution obtained in Scenario 2 in the case when the objective is to satisfy $80 \%$ of the overall demand of relief materials at Layer 1, 2, and 3 as follows:

The supply of $10,360,31,840$, and 13,560 boxes of FA must be ensured to satisfy the demands at Layer 1, 2, and 3, respectively. Similarly, the supply of 17,520, 51,040, and 20,360 packets of DF must be ensured to satisfy the demand at Layer 1, 2, and 3, respectively. The supply of 21,520, 59,800, and 28,320 quantity of WA pouches must be ensured to satisfy the demands at Layer 1,2, and 3, respectively. The supply of $8760,25,520$, and 11,160 packets of SK must be ensured to satisfy the demands at Layer 1, 2, and 3, respectively. The supply of $3580,12,760$, and 6380 pieces of TT must be ensured to satisfy the demands at Layer 1, 2, and 3, respectively. Finally, the supply of 15,920, 12,760, and 25,120 pieces of BT must be ensured to satisfy the demands at Layer 1, 2, and 3, respectively. The above results will help the disaster management team to plan and maintain the above-mentioned minimum quantities of relief materials to be made available at the MPE to satisfy $80 \%$ of the overall demand at three different layers.

\subsection{Scenario 3. $90 \%$ of overall demand satisfaction for RM at Layer 1, 2, and 3}

The solution obtained for Scenario 3 is as follows:

$x_{111}=300, x_{112}=19,700, x_{113}=7700, x_{114}=300, x_{115}=4700, x_{116}=7700, x_{117}=$ $5375, x_{118}=7700, x_{211}=23,905, x_{212}=29,000, x_{213}=9000, x_{214}=1000, x_{215}=1420$, $x_{216}=9000, x_{217}=1000, x_{218}=14,000, x_{311}=30,685, x_{312}=39,000, x_{313}=1000, x_{314}=$ $1000, x_{315}=1000, x_{316}=6450, x_{317}=14,000, x_{318}=14,000, x_{411}=13,465, x_{412}=400$, $x_{413}=4600, x_{414}=4600, x_{415}=4600, x_{416}=4600, x_{417}=7600, x_{418}=4600, x_{511}=7377$, $x_{512}=200, x_{513}=3755, x_{514}=3800, x_{515}=200, x_{516}=3800, x_{517}=200, x_{518}=3800$, $x_{611}=29,500, x_{612}=29,500, x_{613}=9500, x_{614}=500, x_{615}=1180, x_{616}=9500, x_{617}=$ $500, x_{618}=9500, x_{111}^{L 1}=11,655, x_{211}^{L 1}=19,710, x_{311}^{L 1}=24,210, x_{411}^{L 1}=9855, x_{511}^{L 1}=4027$, $x_{611}^{L 1}=17,910, x_{411}^{L 2}=510, x_{611}^{L 2}=740, x_{123}^{L 2}=4145, x_{223}^{L 2}=28,000, x_{323}^{L 2}=3527, x_{623}^{L 2}=$ $29,000, x_{135}^{L 2}=7400, x_{235}^{L 2}=8000, x_{435}^{L 2}=4200, x_{535}^{L 2}=3555, x_{635}^{L 2}=9000, x_{446}^{L 2}=4200$, $x_{546}^{L 2}=3600, x_{157}^{L 2}=4400, x_{257}^{L 2}=420, x_{457}^{L 2}=4200, x_{658}^{L 2}=680, x_{169}^{L 2}=7400, x_{269}^{L 2}=8000$, $x_{369}^{L 2}=4450, x_{469}^{L 2}=4200, x_{569}^{L 2}=3600, x_{669}^{L 2}=9000, x_{1811}^{L 2}=5075, x_{3811}^{L 2}=13,000, x_{4812}^{L 2}=$ $4200, x_{5812}^{L 2}=3600, x_{6812}^{L 2}=9000, x_{211}^{L 3}=22,905, x_{311}^{L 3}=29,686, x_{411}^{L 3}=12,555, x_{511}^{L 3}=$ $7177, x_{611}^{L 3}=28,260, x_{128}^{L 3}=15,255, x_{326}^{L 3}=2175$.

We summarize the solution obtained in Scenario 3 in the case when the objective is to satisfy $90 \%$ of the overall demand of relief materials at Layer 1, 2, and 3 as follows:

The supply of $11,655,35,820$, and 15,255 boxes of FA must be ensured to satisfy the demands at Layer 1, 2, and 3, respectively. Similarly, the supply of 19,710, 57,420, and 22,905 packets of DF must be ensured to satisfy the demand at Layer 1, 2, and 3, respectively. The supply of 24,210, 67,275, and 31,860 quantity of WA pouches must be ensured to satisfy the demands at Layer 1, 2, and 3, respectively. The supply of 9855, 28,710, and 12,555 packets of SK must be ensured to satisfy the demands at Layer 1, 2, and 3, respectively. The supply of $4027,14,355$, and 7177 pieces of TT must be ensured to satisfy the demands at Layer 1, 2, and 3, respectively. Finally, the supply of 17,910, 57,420, and 28,260 pieces of BT must be ensured to satisfy the demands at Layer 1, 2, and 3, respectively. The above results will help the disaster management team to plan and maintain the above-mentioned minimum quantities of relief materials to be made available at the MPE to satisfy $90 \%$ of the overall demand at three different layers. 
Fig. 1 Comparison of cost for different scenarios

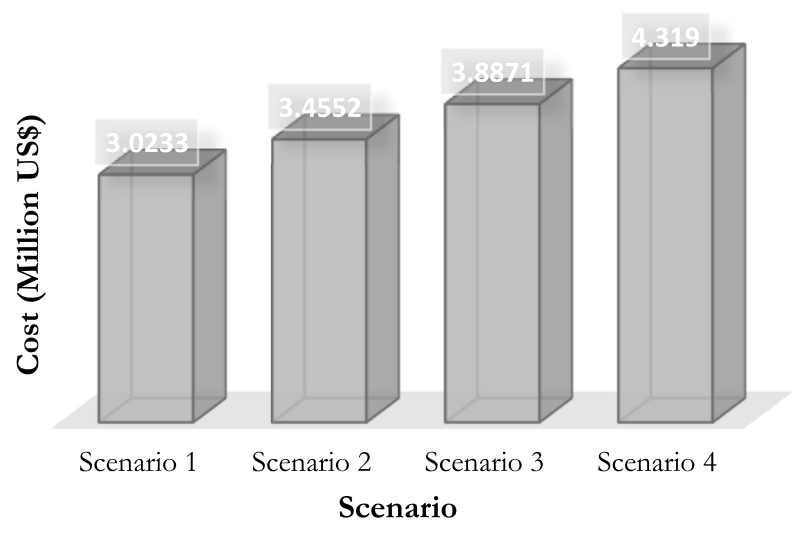

\subsection{Scenario 4. $100 \%$ of overall demand satisfaction for RM at Layer 1, 2, and 3}

The solution obtained for Scenario 3 is as follows:

$x_{111}=17,250, x_{112}=19,700, x_{113}=1500, x_{114}=300, x_{115}=4700, x_{116}=7700, x_{117}=$ $300, x_{118}=7700, x_{211}=26,450, x_{212}=29,000, x_{213}=9000, x_{214}=1000, x_{215}=7800$, $x_{216}=9000, x_{217}=1000, x_{218}=14,000, x_{311}=34,882, x_{312}=39,000, x_{313}=5268$, $x_{314}=1000, x_{315}=1000, x_{316}=9000, x_{317}=14,000, x_{318}=14,000, x_{411}=14,350, x_{412}=$ $12,500, x_{413}=4600, x_{414}=400, x_{415}=4600, x_{416}=4600, x_{417}=7600, x_{418}=400, x_{511}=$ $8175, x_{512}=200, x_{513}=3800, x_{514}=200, x_{515}=1750, x_{516}=3800, x_{517}=3800, x_{518}=$ $3800, x_{611}=29,500, x_{612}=29,500, x_{613}=9500, x_{614}=500, x_{615}=9500, x_{616}=9500$, $x_{617}=1700, x_{618}=9500, x_{111}^{L 1}=12,950, x_{211}^{L 1}=21,900, x_{311}^{L 1}=26,900, x_{411}^{L 1}=10,950$, $x_{511}^{L 1}=4475, x_{611}^{L 1}=19,900, x_{123}^{L 2}=19,400, x_{223}^{L 2}=28,000, x_{323}^{L 2}=36,482, x_{423}^{L 2}=12,100$, $x_{623}^{L 2}=26,600, x_{135}^{L 2}=1200, x_{235}^{L 2}=8000, x_{336}^{L 2}=4268, x_{435}^{L 2}=4200, x_{535}^{L 2}=3600, x_{635}^{L 2}=$ $9000, x_{157}^{L 2}=4400, x_{257}^{L 2}=6800, x_{457}^{L 2}=4200, x_{557}^{L 2}=1550, x_{658}^{L 2}=9000, x_{169}^{L 2}=7400, x_{269}^{L 2}=$ $8000, x_{369}^{L 2}=8000, x_{469}^{L 2}=4200, x_{569}^{L 2}=3600, x_{669}^{L 2}=9000, x_{3811}^{L 2}=13,000, x_{4811}^{L 2}=7200$, $x_{5811}^{L 2}=3600, x_{1812}^{L 2}=7400, x_{2812}^{L 2} \stackrel{1}{=} 13,000, x_{3812}^{L 2}=13,000, x_{5812}^{L 2}=3600, x_{6812}^{L 2}=9000$,

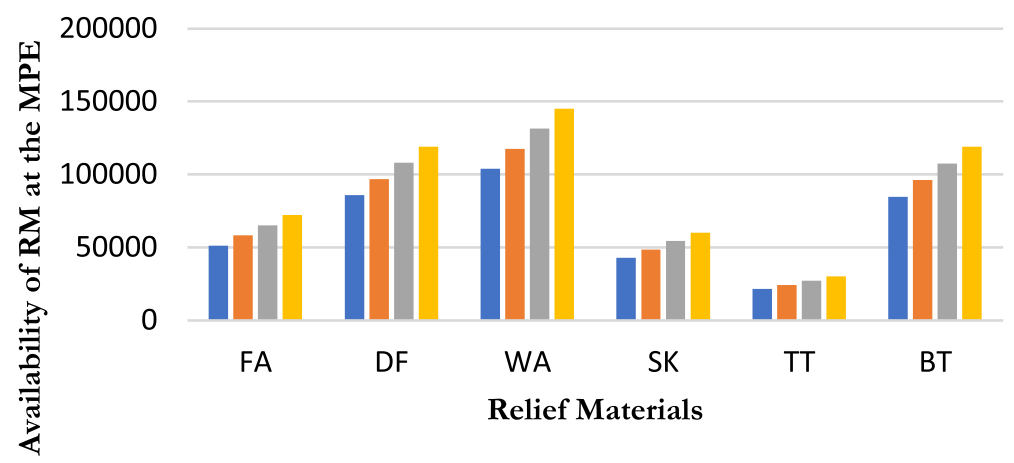

- Scenario $1 \quad$ Scenario $2 \quad$ Scenario $3 \quad$ Scenario 4

Fig. 2 Minimum availability of RMs at the MPE 
$x_{111}^{L 3}=16,950, x_{211}^{L 2}=25,450, x_{311}^{L 2}=22,882, x_{411}^{L 2}=13,950, x_{511}^{L 2}=7975, x_{611}^{L 2}=29,000$, $x_{326}^{L 2}=1518, x_{626}^{L 2}=2400$.

We summarize the solution obtained in Scenario 4 in the case when the objective is to satisfy $100 \%$ of the overall demand of relief materials at Layer 1, 2, and 3 as follows:

The supply of $12,950,39,800$, and 16,950 boxes of FA must be ensured to satisfy the demands at Layer 1, 2, and 3, respectively. Similarly, the supply of 21,900, 63,800, and 25,450 packets of DF must be ensured to satisfy the demand at Layer 1, 2, and 3, respectively. The supply of 26,900, 74,750, and 35,400 quantities of WA pouches must be ensured to satisfy the demands at Layer 1, 2, and 3, respectively. The supply of 10,950, 31,900, and 13,950 packets of SK must be ensured to satisfy the demands at Layer 1, 2, and 3, respectively. The supply of 4475, 15,950, and 7975 pieces of TT must be ensured to satisfy the demands at Layer 1, 2, and 3, respectively. Finally, the supply of 19,900, 63,800, and 31,400 pieces of BT must be ensured to satisfy the demands at Layer 1, 2, and 3 , respectively. The above results will help the disaster management team to plan and maintain the above-mentioned minimum quantities of relief materials to be made available at the MPE to satisfy $100 \%$ of the overall demand at three different layers.

The supply of RM to the affected areas incurs a considerable cost in an emergency. Therefore, the total cost is an essential factor in making supply decisions. We now analyze the cost in the considered scenarios and present the comparison in Fig. 1.

Figure 1 shows that the cost incurred to satisfy $70 \%, 80 \%, 90 \%$, and $100 \%$ of the demand of RM at the three layers are US\$ 3.0233, US\$ 3.4552, US\$ 3.8871, and US\$ 4.319 million, respectively. So, the total cost of supplying emergency relief materials to the affected areas increases with the increase in the percentage of satisfying demands.

Next, we estimate the minimum level of individual relief materials that are to be ensured at the MPE so that the demands for different scenarios can be fulfilled in the affected areas. Figure 2 presents the number of units of individual relief materials to be supplied to Layer 1,2 , and 3 in different scenarios.

From Fig. 2, we find that the minimum quantity of FA to be maintained at the MPE for Scenarios 1, 2, 3, and 4 are 51,190, 58,160,65,130, and 72,100, respectively. Similarly, for DF, the respective quantities are 85,805, 96,920, 108,035, 119,150. For WA, the respective quantities are 103,935,117,640,131,345, and 145,050. For SK, the respective quantities are 42,960, 48,640, 54,320, and 60,000. For TT, the respective quantities are 21,480, $24,320,27,160,30,000$. Finally, for BT, the respective quantities are 84,570, 96,080, $107,590,119,100$.

While comparing our findings with the previous literature, we agree with Gralla et al. (2014) that the comparison is not easy as each model is different from the other due to various reasons. However, some of the major similarities and dissimilarities are identified. We primarily capture and quantify the trade-offs between the total cost of supplying the RM and demand satisfaction. From this point of view, our findings are in line with Vitoriano et al. (2011), Bozorgi-Amiri et al. (2013), Bastian et al. (2016), Ransikarbum and Mason (2016), and Sarma et al. (2020). In particular, the trade-offs between demand and supply (Vitoriano et al., 2011), demand and cost (Bozorgi-Amiri et al., 2013), budget, demand, and response time (Bastian et al., 2016), resources and budget (Ransikarbum \& Mason, 2016; Sarma et al., 2020) are quantified. On the other hand, our study is unique in terms of the mathematical model and quantifying uncertainties. Authors use goal programming (Bastian et al., 2016; Ransikarbum \& Mason, 2016; Vitoriano et al., 2011), fuzzy logic (Sarma et al., 2020), and robust optimization (Bozorgi-Amiri et al., 2013). The present study uses a novel probabilistic-fuzzy goal programming model. Like the present study, 
Baharmand et al. (2020) also consider the 2015 Nepal Earthquake problem. However, the objective of the study is to locate temporary relief distribution centers.

\section{Theoretical and managerial implications}

This research has significant theoretical and managerial implications. First, it introduces a novel probabilistic fuzzy goal programming model to the humanitarian logistics literature to manage the supply of emergency relief materials in the post-disaster phase. The goals of the model are probabilistic as well as fuzzy in nature. The concept is highly effective in capturing the uncertainty of the decision-making environment related to relief distribution. Let us consider the example of the cost goal, say. The probability that the total cost of relief operations is less than or equal to an estimated total cost is 'fuzzily greater than or equal to' to some given satisfaction level. We introduce the 'fuzzily greater than or equal to' over the strict satisfaction level because there is no certainty that the cost goal will be satisfied with a probability of 0.98 , say. This kind of strict inequality in the goal satisfaction level leads to non-satisfaction with the goal. Therefore, it is not possible to find any solution to such a problem. On the contrary, the 'fuzzily greater than or equal to' satisfaction level of the goal is more practical in the real-world situation and offers flexibility to the decision-maker.

The proposed setting will also ensure the best compromise solution under the given set of system constraints arising from the disaster relief distribution problem. In the previous section, we compare the relief distribution models proposed by various researchers and how they capture the trade-offs between the total cost of supplying the relief materials and demand satisfaction. We find the existence of deterministic and stochastic models only for capturing the trade-offs. Apart from this, we derive the deterministic counterpart of the proposed model under the assumption that the probability distribution of demands of relief materials follows a uniform distribution. Through Propositions 1 and 2, we prove the equivalence of the original and derived models. These aspects demonstrate the theoretical contributions of the paper.

Second, this research will help the policymakers and humanitarian actors design and execute an effective emergency relief distribution plan for helping the affected people. After analyzing various demand scenarios under the complex trade-offs between the probability of satisfying demands and cost incurred to transport them to the affected areas with uncertain satisfaction level, we get a clear idea about what will be the minimum level of which emergency relief materials so that the demand can be fulfilled by incurring least cost. In other words, we can say that the proposed research will help the disaster management authority to better coordinate the supply of the RM with different nodes in the relief distribution chain. In the case of a shortage of relief materials at the MPE, measures can be taken by coordinating with the respective humanitarian organizations and countries to provide such aids. So, the proposed model's solution will help improve managerial understanding in a critical and uncertain situation. The emergency relief distribution decisionmakers can apply the suggested model to obtain the best-compromised solution under the presence of stochastic and fuzzy uncertainties. 


\section{Conclusions}

The problem of the post-disaster supply of emergency RM was studied. It was challenging as the supply of multiple RM were to be supplied to PD located in three different layers that are accessible through separate models of transports. Moreover, accessing the demand precisely immediately after the disaster was almost an impossible task. So, the demands for RM, and hence the corresponding cost of supply, were modeled as random variables. A new PFGP model was proposed to formulate the problem. Under the assumption of uniform demands of RM, an equivalent model was derived. Finally, the model was solved using the DE. The proposed model was applied to a case example that was designed based on the Nepal Earthquake in 2015. Four different scenarios of demands of RM at the three layers and costs were investigated. The major contribution of this research is to manage the supply of RM to maintain the minimum level of each of the RM so that demands can be fulfilled at the PD.

The assumption of uniform distribution for the demands of RM at the PD is a limitation of this work. Because of the non-availability of historical data, such an assumption was made. The distribution of demands for each RM at the PD could be estimated if historical data were available. In such a case, the derivation of the equivalent model may not be possible. However, Monte-Carlo simulation-based search techniques (Jana \& Biswal, 2004; Jana \& Sharma, 2010) may be designed to overcome this challenge. There are various AIbased search techniques available. They may also be applied to find the solution to the PFGP problem.

The proposed approach may be applied to manage the supply of RM in disasters other than earthquakes. The work could be extended to manage the supply of emergency RM in pandemic situations like COVID-19 to help thousands of migrant workers who were stuck due to the lockdown for several weeks without proper food and basic necessities. The model can also be extended to address the trade-offs among conflicting goals appearing in business logistics problems under uncertainties. It will be interesting to study the proposed model by incorporating goals like the time required to supply the relief materials and equity.

Acknowledgements The authors thank the Guest Editor and reviewers for their insightful comments to improve the paper.

\section{References}

Abazari, S. R., Aghsami, A., \& Rabbani, M. (2020). Prepositioning and distributing relief items in humanitarian logistics with uncertain parameters. Socio-Economic Planning Sciences. https://doi.org/10. 1016/j.seps.2020.100933

Baharmand, H., Comes, T., \& Lauras, M. (2020). Supporting group decision makers to locate temporary relief distribution centres after sudden-onset disasters: A case study of the 2015 Nepal earthquake. International Journal of Disaster Risk Reduction, 45, 101455. https://doi.org/10.1016/j.ijdrr.2019. 101455

Bastian, N. D., Griffin, P. M., Spero, E., \& Fulton, L. V. (2016). Multi-criteria logistics modeling for military humanitarian assistance and disaster relief aerial delivery operations. Optimization Letters, 10(5), 921-953.

Behl, A., \& Dutta, P. (2020). Engaging donors on crowdfunding platform in Disaster Relief Operations (DRO) using gamification: A Civic Voluntary Model (CVM) approach. International Journal of Information Management, 54, 102140. https://doi.org/10.1016/j.ijinfomgt.2020.102140 
Behl, A., \& Dutta, P. (2020a). Social and financial aid for disaster relief operations using CSR and crowdfunding: Moderating effect of information quality. Benchmarking: an International Journal, 27(2), 732-759.

Bozorgi-Amiri, A., Jabalameli, M. S., \& Al-e-Hashem, S. M. (2013). A multi-objective robust stochastic programming model for disaster relief logistics under uncertainty. Or Spectrum, 35(4), 905-933.

Cao, C., Liu, Y., Tang, O., \& Gao, X. (2021). A fuzzy bi-level optimization model for multi-period postdisaster relief distribution in sustainable humanitarian supply chains. International Journal of Production Economics. https://doi.org/10.1016/j.ijpe.2021.108081

CDPS. (2016). Nepal earthquake 2015: A socio-demographic impact study. Tribhuwan University.

Charles, A., Lauras, M., Van Wassenhove, L. N., \& Dupont, L. (2016). Designing an efficient humanitarian supply network. Journal of Operations Management, 47, 58-70.

Chen, Y. X., Tadikamalla, P. R., Shang, J., \& Song, Y. (2020). Supply allocation: Bi-level programming and differential evolution algorithm for natural disaster relief. Cluster Computing, 23(1), 203-217.

Chong, M., Lazo Lazo, J. G., Pereda, M. C., \& Machuca De Pina, J. M. (2019). Goal programming optimization model under uncertainty and the critical areas characterization in humanitarian logistics management. Journal of Humanitarian Logistics and Supply Chain Management, 9(1), 82-107.

Das, S., \& Suganthan, P. N. (2010). Differential evolution: A survey of the state-of-the-art. IEEE Transactions on Evolutionary Computation, 15(1), 4-31.

Das, S., Mullick, S. S., \& Suganthan, P. N. (2016). Recent advances in differential evolution-an updated survey. Swarm and Evolutionary Computation, 27, 1-30.

Day, J. M. (2014). Fostering emergent resilience: The complex adaptive supply network of disaster relief. International Journal of Production Research, 52(7), 1970-1988.

Day, J. M., Melnyk, S. A., Larson, P. D., Davis, E. W., \& Whybark, D. C. (2012). Humanitarian and disaster relief supply chains: A matter of life and death. Journal of Supply Chain Management, 48(2), 21-36.

Dubey, R., \& Gunasekaran, A. (2016). The sustainable humanitarian supply chain design: Agility, adaptability and alignment. International Journal of Logistics Research and Applications, 19(1), 62-82.

Dubey, R., Altay, N., \& Blome, C. (2019a). Swift trust and commitment: The missing links for humanitarian supply chain coordination? Annals of Operations Research, 283(1), 159-177.

Dubey, R., Gunasekaran, A., \& Papadopoulos, T. (2019b). Disaster relief operations: Past, present and future. Annals of Operations Research, 283(1), 1-8.

Faiz, T. I., \& Vogiatzis, C. (2020). Two-echelon vehicle and UAV routing for post-disaster humanitarian operations with uncertain demand. arXiv preprint arXiv:2001.06456

Gralla, E., Goentzel, J., \& Fine, C. (2014). Assessing trade-offs among multiple objectives for humanitarian aid delivery using expert preferences. Production and Operations Management, 23(6), 978-989.

Grass, E., \& Fischer, K. (2016). Two-stage stochastic programming in disaster management: A literature survey. Surveys in Operations Research and Management Science, 21(2), 85-100.

Hong, J. D., Jeong, K. Y., \& Feng, K. (2015). Emergency relief supply chain design and trade-off analysis. Journal of Humanitarian Logistics and Supply Chain Management., 5(2), 162-187.

Jana, R. K., \& Biswal, M. P. (2004). Stochastic simulation-based genetic algorithm for chance constraint programming problems with continuous random variables. International Journal of Computer Mathematics, 81(9), 1069-1076.

Jana, R. K., Sharma, D. K., \& Chakraborty, B. (2016). A hybrid probabilistic fuzzy goal programming approach for agricultural decision-making. International Journal of Production Economics, 173, 134-141.

Jana, R. K., Chandra, C. P., \& Tiwari, A. K. (2019). Humanitarian aid delivery decisions during the early recovery phase of disaster using a discrete choice multi-attribute value method. Annals of Operations Research, 283(1), 1211-1225.

Lieckens, K., \& Vandaele, N. (2016). Differential evolution to solve the lot size problem in stochastic supply chain management systems. Annals of Operations Research, 242(2), 239-263.

Lin, Y. H., Batta, R., Rogerson, P. A., Blatt, A., \& Flanigan, M. (2011). A logistics model for emergency supply of critical items in the aftermath of a disaster. Socio-Economic Planning Sciences, 45(4), $132-145$.

Liu, Z., \& Nagurney, A. (2013). Supply chain networks with global outsourcing and quick-response production under demand and cost uncertainty. Annals of Operations Research, 208(1), 251-289.

Liu, Y., Lei, H., Zhang, D., \& Wu, Z. (2018). Robust optimization for relief logistics planning under uncertainties in demand and transportation time. Applied Mathematical Modelling, 55, 262-280.

Lusk, E. J., \& Wright, H. (1982). Deriving the probability density for sums of uniform random variables. The American Statistician, 36(2), 128-130. 
Maiyar, L. M., \& Thakkar, J. J. (2020). Robust optimisation of sustainable food grain transportation with uncertain supply and intentional disruptions. International Journal of Production Research, 58(18), 5651-5675.

Manopiniwes, W., \& Irohara, T. (2017). Stochastic optimisation model for integrated decisions on relief supply chains: Preparedness for disaster response. International Journal of Production Research, 55(4), 979-996.

Mohamed, R. H. (1992). A chance-constrained fuzzy goal program. Fuzzy Sets and Systems, 47(2), $183-186$.

Najafi, M., Eshghi, K., \& Dullaert, W. (2013). A multi-objective robust optimization model for logistics planning in the earthquake response phase. Transportation Research Part E: Logistics and Transportation Review, 49(1), 217-249.

Narasimhan, R. (1980). Goal programming in a fuzzy environment. Decision Sciences, 11(2), 325-336.

National Planning Commission (NPC). (2015). Nepal earthquake post disaster needs assessment. NPC.

Özdamar, L., Ekinci, E., \& Küçükyazici, B. (2004). Emergency logistics planning in natural disasters. Annals of Operations Research, 129(1), 217-245.

Papathanasiou, J., \& Ploskas, N. (2018). Goal programming. In Multiple criteria decision aid (pp. 131164). Springer, Cham.

Park, J. H., Kazaz, B., \& Webster, S. (2018). Surface versus air shipment of humanitarian goods under demand uncertainty. Production and Operations Management, 27(5), 928-948.

Ransikarbum, K., \& Mason, S. J. (2016). Goal programming-based post-disaster decision making for integrated relief distribution and early-stage network restoration. International Journal of Production Economics, 182, 324-341.

Team, R. C. (2013). R: A language and environment for statistical computing. R Foundation for Statistical Computing, Vienna, Austria. URL https://www.r-project.org/.

Rezaee, A., Dehghanian, F., Fahimnia, B., \& Beamon, B. (2017). Green supply chain network design with stochastic demand and carbon price. Annals of Operations Research, 250(2), 463-485.

Routroy, S., \& Kodali, R. (2005). Differential evolution algorithm for supply chain inventory planning. Journal of Manufacturing Technology Management, 16(1), 7-17.

Sarma, D., Das, A., \& Bera, U. K. (2020). An optimal redistribution plan considering aftermath disruption in disaster management. Soft Computing, 24(1), 65-82.

Schwendinger, F. (2019). 'DEoptim' and 'DEoptimR' Plugin for the 'R' Optimization Interface.

Shafiq, M., \& Soratana, K. (2020). Lean readiness assessment model-a tool for Humanitarian Organizations' social and economic sustainability. Journal of Humanitarian Logistics and Supply Chain Management, 10(2), 77-99.

Sharma, H., Sharma, D., \& Jana, R. K. (2009). Credit union portfolio management-An additive fuzzy goal programming approach. International Research Journal of Finance and Economics, 30(1), 18-29.

Storn, R., \& Price, K. (1997). Differential evolution-a simple and efficient heuristic for global optimization over continuous spaces. Journal of Global Optimization, 11(4), 341-359.

Sun, J., Chai, R., \& Nakade, K. (2018). A study of stochastic optimization problem for humanitarian supply chain management. Journal of Advanced Mechanical Design, Systems, and Manufacturing, 12(3), JAMDSM0066-JAMDSM0066.

Tofighi, S., Torabi, S. A., \& Mansouri, S. A. (2016). Humanitarian logistics network design under mixed uncertainty. European Journal of Operational Research, 250(1), 239-250.

Tomasini, R. M., \& Van Wassenhove, L. N. (2009). From preparedness to partnerships: Case study research on humanitarian logistics. International Transactions in Operational Research, 16(5), 549-559.

UN OCHA. (2018). World Humanitarian Data and Trends 2018. United Nations.

United Nations World Food Programme (UN-WFP). (2015). El Niño : Implications and Scenarios for 2015. VAM-Food Security Analysis.

UNWFP, Situation Report 21.05.2015, Technical Report United Nations World Food Programme (UNWFP), 2015.

Vitoriano, B., Ortuno, T., \& Tirado, G. (2009). HADS, a goal programming-based humanitarian aid distribution system. Journal of Multi-Criteria Decision Analysis, 16(1-2), 55-64.

Vitoriano, B., Ortuño, M. T., Tirado, G., \& Montero, J. (2011). A multi-criteria optimization model for humanitarian aid distribution. Journal of Global Optimization, 51(2), 189-208.

Wang, X., Choi, T. M., Liu, H., \& Yue, X. (2016a). A novel hybrid ant colony optimization algorithm for emergency transportation problems during post-disaster scenarios. IEEE Transactions on Systems, Man, and Cybernetics: Systems, 48(4), 545-556.

Wang, X., Wu, Y., Liang, L., \& Huang, Z. (2016b). Service outsourcing and disaster response methods in a relief supply chain. Annals of Operations Research, 240(2), 471-487. 
Yu, X., Li, C., Zhao, W. X., \& Chen, H. (2020). A novel case adaptation method based on differential evolution algorithm for disaster emergency. Applied Soft Computing, 92, 106306. https://doi.org/10.1016/j. asoc.2020.106306

Yu, L., Zhang, C., Jiang, J., Yang, H., \& Shang, H. (2021). Reinforcement learning approach for resource allocation in humanitarian logistics. Expert Systems with Applications, 173, 114663.

Zheng, Y. J., \& Ling, H. F. (2013). Emergency transportation planning in disaster relief supply chain management: A cooperative fuzzy optimization approach. Soft Computing, 17(7), 1301-1314.

Zhu, L., Gong, Y., Xu, Y., \& Gu, J. (2019). Emergency relief routing models for injured victims considering equity and priority. Annals of Operations Research, 283(1), 1573-1606.

Zimmermann, H. J. (1978). Fuzzy programming and linear programming with several objective functions. Fuzzy Sets and Systems, 1(1), 45-55.

Zokaee, S., Bozorgi-Amiri, A., \& Sadjadi, S. J. (2016). A robust optimization model for humanitarian relief chain design under uncertainty. Applied Mathematical Modelling, 40(17-18), 7996-8016.

Publisher's Note Springer Nature remains neutral with regard to jurisdictional claims in published maps and institutional affiliations. 